\title{
Real-time and nested polymerase chain reaction in the diagnosis of multifocal serpiginoid choroiditis caused by Mycobacterium tuberculosis - a case report
}

Sachin B Shetty ${ }^{1}$, Jyotirmay Biswas ${ }^{2^{*}}$ and Sowmiya Murali ${ }^{3}$

\begin{abstract}
Background: The term multifocal serpiginoid choroiditis (MSC) has been proposed for the infective variant of serpiginous choroiditis (SC) to distinguish it from typical SC believed to be autoimmune related. The role of Mycobacterium tuberculosis (MTb) in MSC has been studied by conventional polymerase chain reaction (PCR). However, the use of real-time PCR (RT-PCR) and nested PCR (N-PCR) in MSC has not been reported. This paper aims to highlight the usefulness of PCR in identifying MTb as a causative agent for MSC leading to its correct treatment with anti-tubercular therapy (ATT).
\end{abstract}

Findings: A young male with a family history of tuberculosis (TB) presented with a history of diminution of vision (DOV) since 3 months in his right eye (RE). He gave similar history in his left eye (LE) since 3 years. His fundus findings were suggestive of MSC. His high-resolution computed tomography (HRCT) chest and Quanti-FERON TB gold results were positive for MTb. These suggested TB to be the likely cause for MSC. This was confirmed by a positive N-PCR report of his aqueous specimen. Further RT-PCR was done to quantify the bacillary load before starting therapy. He was advised 9 months of ATT with 6 weeks of oral steroids. At last follow-up, the RE showed better healing than the LE with fewer chorioretinal scars and a better visual acuity.

Conclusions: RT and N-PCR for MTb are useful in establishing a tuberculous etiology in MSC. Coupled with a good response to ATT, these tests justify the use of ATT in MSC with a PCR-confirmed MTb report.

Keywords: Multifocal serpiginoid choroiditis; Serpiginous choroiditis; Real-time PCR; Nested PCR

\section{Findings}

\section{Introduction}

Serpiginous choroiditis (SC) is used to describe a bilateral chronic recurrent geographic pattern of choroiditis that typically extends from the peripapillary area and affects the overlying retinal pigment epithelium (RPE) and outer retina [1]. Autoimmune [2], infective [3], vascular, and degenerative mechanisms have all been proposed in its etiopathogenesis. The infectious type of SC is mostly commonly associated with tuberculosis (TB). Other causes include herpes viruses, syphilis, fungi, and toxoplasma [4].

\footnotetext{
* Correspondence: drjb@snmail.org

${ }^{2}$ Uveitis \& Ocular Pathology Department, Vision Research Foundation, 18,

College Road, Nungambakkam, Chennai 600006, Tamil Nadu, India

Full list of author information is available at the end of the article
}

Recently, Nazari and Rao [4] proposed the term multifocal serpiginoid choroiditis (MSC) for the infective variant of $\mathrm{SC}$ to distinguish it from typical SC.

\section{Background}

A study of MSC patients with polymerase chain reaction (PCR) by Mohan et al. [5] concluded that Mycobacterium tuberculosis (MTb) (53.8\%) was the most common and important etiologic agent for MSC in TB endemic areas. One of the drawbacks of their study was that DNA copy numbers were not assessed by real-time PCR (RT-PCR). Annamalai et al. [6] used RT-PCR in 29 cases of typical SC and demonstrated MTb DNA in only 1 case, thus concluding a chance/rare association of TB with SC. In 
this series, nested PCR (N-PCR) was not performed in the positive case.

Herein, we report a case of MSC which was proved to be caused by MTb by both RT-PCR and N-PCR. To our knowledge, this is the first case report where both RTPCR and nested PCR were used to show an association between TB and MSC.

\section{Case description}

A 31-year-old male from Central India presented with a history of painless progressive diminution of vision (DOV) with floaters since 3 months in his right eye (RE). He was treated elsewhere with a short course of oral steroid over 1 month. Since 6 days, he noticed a further drop in his RE vision and was referred to us. He also had a similar history of sudden DOV in his left eye (LE) which was untreated and has been constant since 3 years. He had a family history of TB with both of his parents treated for the same.

On examination, the best corrected visual acuity (BCVA) in the RE was 3/60 (20/400), <N36, and in the LE was counting fingers close to face (CFCF), $<$ N36 for distance and near, respectively. Anterior segment and intraocular pressures were normal in both eyes (BE). Fundus evaluation of the RE showed multiple discrete areas of active choroiditis amidst areas of chorioretinal atrophic (CRA) scars and vitritis grade 2 (Figure 1). The LE showed occasional vitreous cells and multiple healed CRA scars all over the fundus with subretinal fibrosis involving the macula (Figure 2). High-resolution computed tomography (HRCT) chest showed tiny multiple mediastinal adenopathy suggestive of TB. Quanti-FERON TB gold test (Cellestis Limited, Carnegie, Victoria, Australia) was positive. Rapid plasma reagin and Treponema pallidum hemagglutination assay were negative. These features were suggestive of MSC secondary to TB in BE with reactivation in the RE. The etiological diagnosis was confirmed by positive $\mathrm{N}$ PCR (Figure 3) and RT-PCR report of aqueous specimen (Additional file 1). After a physician clearance, the patient was advised a 9-month course of antitubercular therapy (ATT) with a tapering course of oral steroids over 6 weeks. At his last follow-up, at 4 months after initiating ATT, his right eye had a BCVA of 20/125 (6/36) with healed chorioretinal scars (Figure 4 and Figure 5).

\section{Discussion}

This case report demonstrates both RT and N-PCR positivity in a case of MSC, establishing tuberculous etiology

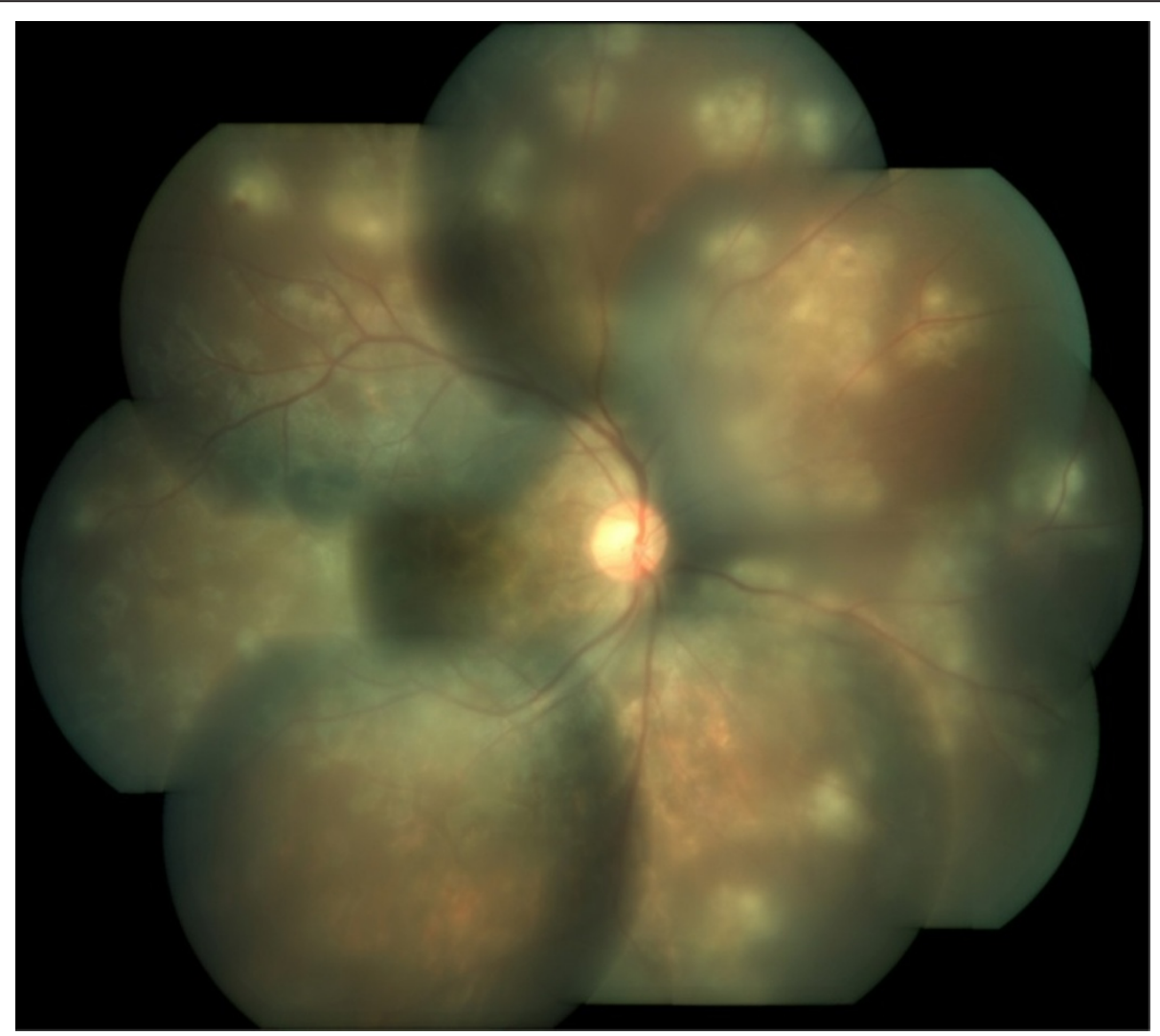

Figure 1 Active multifocal serpiginoid choroiditis. Montage picture of the right eye showing multiple discrete areas of active choroiditis amidst areas of healed chorioretinal atrophic scars with grade 2 vitritis at presentation. 


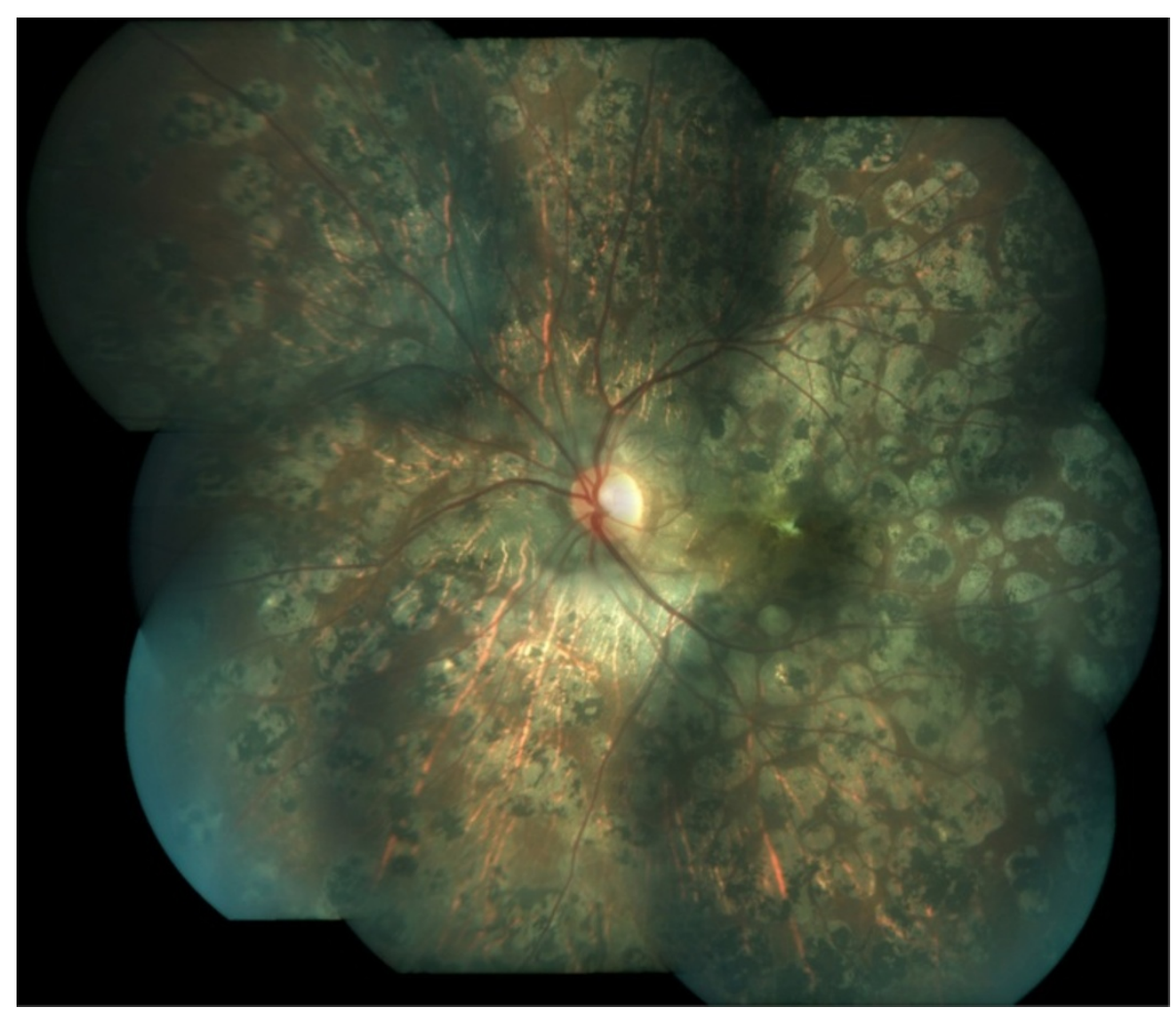

Figure 2 Healed multifocal serpiginoid choroiditis. Montage picture of the left eye showing multiple healed chorioretinal scars with subretinal fibrosis at the macula at presentation.

conclusively. It justifies the use of ATT in MSC patients with a PCR-confirmed MTb report. Under ATT cover, the patient's RE healed better than the LE with fewer chorioretinal scars and a better visual acuity $(20 / 125$ versus CFCF). Not only is ATT the definitive and specific treatment in these cases, but it also prevents recurrence of uveitic attacks [7].

RT-PCR can detect, amplify, and quantify the bacillary load in real time thus giving an idea about the disease severity. Serial monitoring of RT-PCR after starting

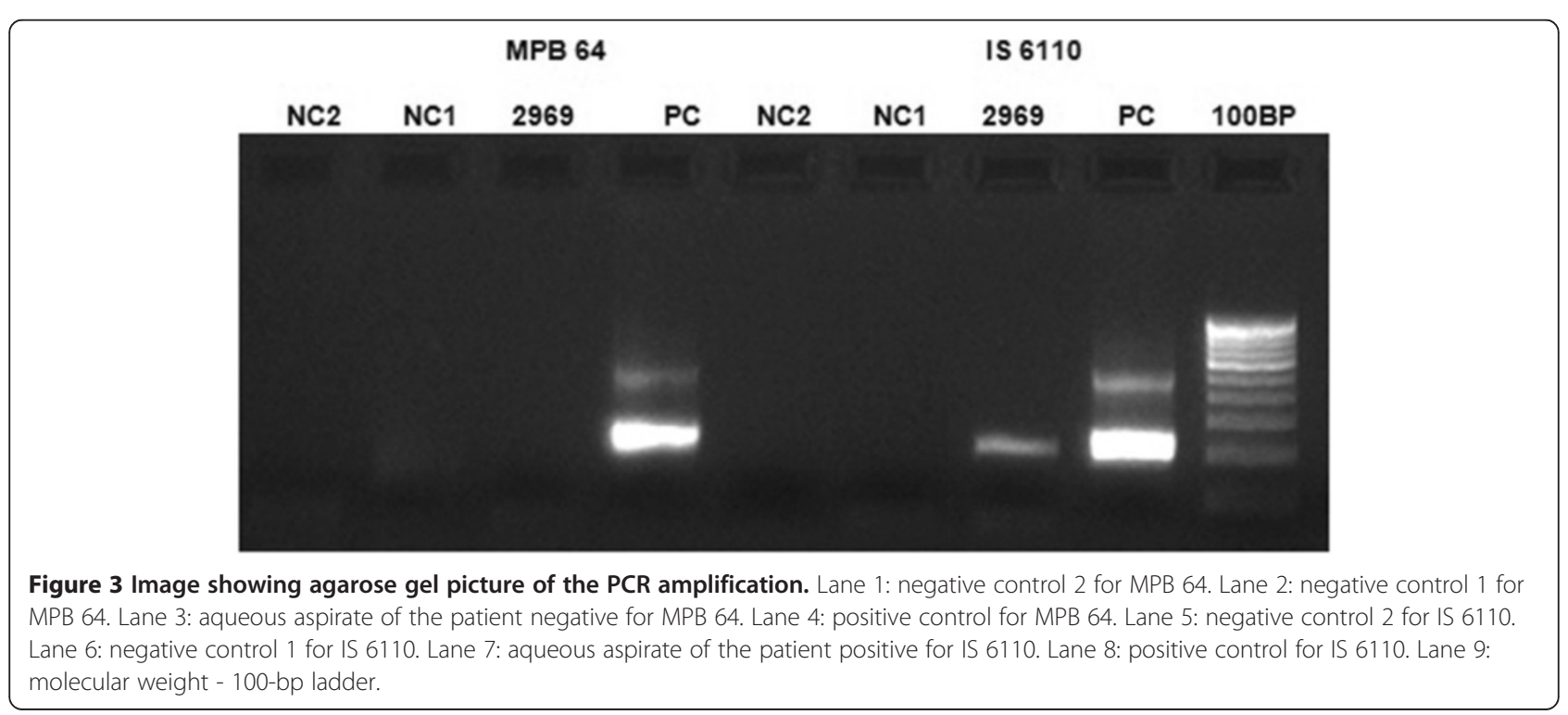




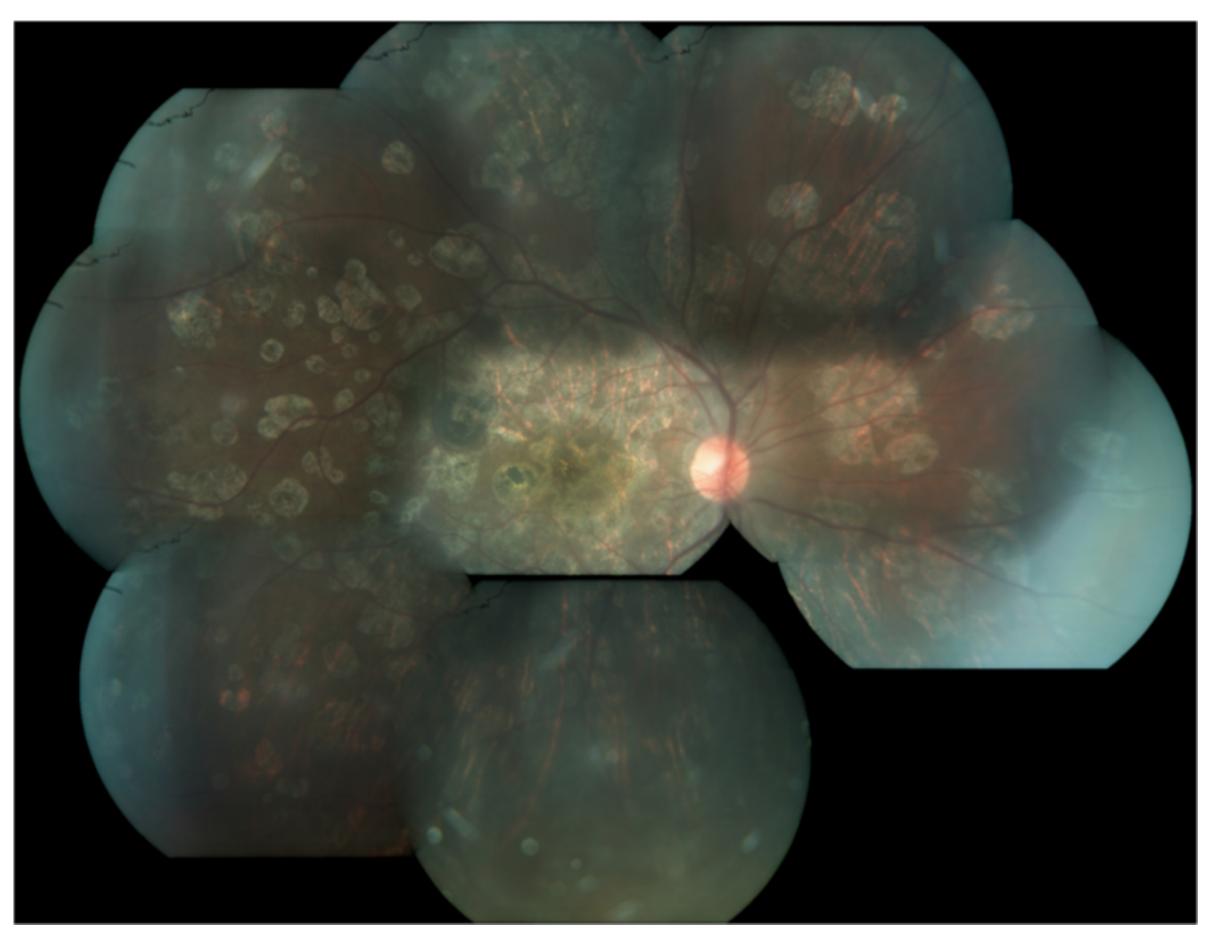

Figure 4 Healed multifocal serpiginoid choroiditis. Montage picture of the right eye showing resolution of active choroiditis leaving behind multiple healed chorioretinal scars at the end of the fourth month after initiation of antitubercular therapy.

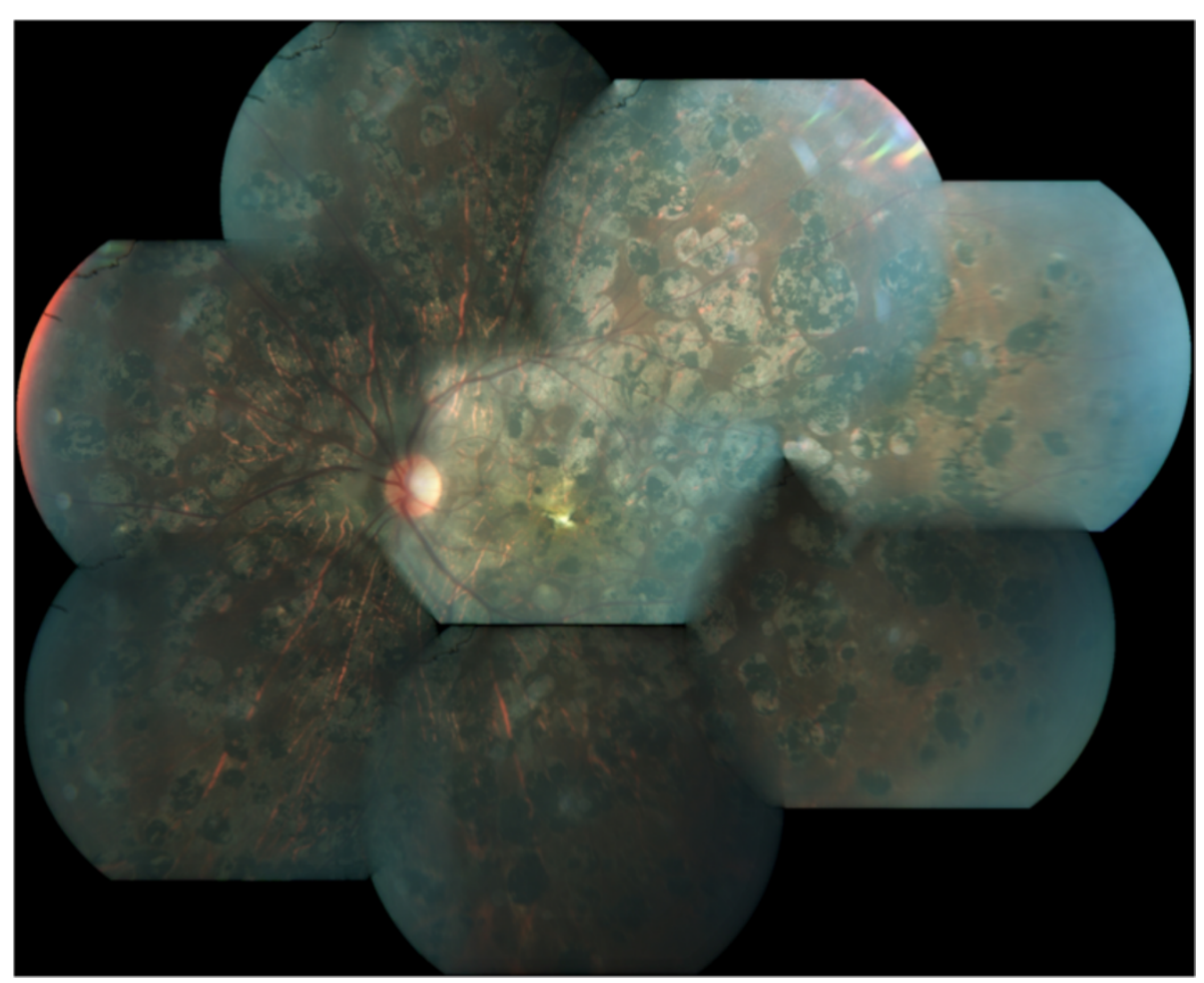

Figure 5 Healed multifocal serpiginoid choroiditis. Montage picture of the left eye showing multiple healed chorioretinal scars with subretinal fibrosis at the macula at the fourth month follow-up. 
treatment may show reduced number of DNA copies, thus indicating a beneficial response to therapy. In this case, however, due to ethical, logistical, and lack of patient's consent, we could not repeat RT-PCR during the follow-up visits. Hence, we could not correlate RTPCR with disease severity or treatment response to ATT. Properly designed prospective studies may demonstrate this correlation.

Nested PCR [8] is a modification of conventional PCR intended to reduce contaminations in products due to amplification of unexpected primer binding sites. RTPCR is much more expensive and complicated as compared to N-PCR. Hence, N-PCR could be useful initially in establishing the etiological diagnosis and then following it up with RT-PCR later to assess the treatment response. Further studies may help in incorporating PCR (wherever feasible) in the local practice guidelines before prescribing ATT for the MSC cases. This may limit the unwarranted use of ATT and its side effects in nontuberculous choroiditis.

However, a negative PCR from anterior chamber (AC) tap theoretically cannot rule out tuberculous etiology in MSC as AC tap may often be negative as compared to vitreous tap in posterior segment inflammation. A large prospective study is needed to determine the sensitivity and specificity of AC tap.

\section{Consent}

Written informed consent was obtained from the patient for the publication of this report and any accompanying images.

\section{Additional file}

Additional file 1: PCR: quantitation report. Quantitation data for

Cycling A.Green and standard curve.

\section{Abbreviations}

ATT: antitubercular therapy; CRA: chorioretinal atrophic; DOV: diminution of vision; HRCT: high-resolution computed tomography; LE: left eye; MSC: multifocal serpiginoid choroiditis; MTb: Mycobacterium tuberculosis; N-PCR: nested PCR; PCR: polymerase chain reaction; RE: right eye; RT-PCR: real-time PCR; SC: serpiginous choroiditis; TB: tuberculosis.

\section{Competing interests}

The authors declare that they have no competing interests.

\section{Authors' contributions}

SBS participated in obtaining the clinical data, review of the literature, and drafting of the manuscript. JB participated in the critical management in patient care and drafting of the manuscript. SM participated in the PCR analysis. All authors read and approved the final manuscript.

\section{Acknowledgements}

Sachin B Shetty is the submitting author and the first author. This work was primarily carried out at Uvea Department, Sankara Nethralaya, 18, College Road, Nungambakkam, Chennai, 600 006, Tamil Nadu, India.

\section{Author details}

${ }^{1}$ Vitreo-Retina \& Uvea Services, Sadguru Netra Chikitsalaya, Jankikund Post, Chitrakoot, U.P. 210204, India. ' $U$ veitis \& Ocular Pathology Department, Vision Research Foundation, 18, College Road, Nungambakkam, Chennai 600006, Tamil Nadu, India. ${ }^{3}$ Medical Research Foundation, 18, College Road, Sankara Nethralaya, Nungambakkam, Chennai 600006, Tamil Nadu, India.

Received: 5 August 2014 Accepted: 30 October 2014

Published online: 18 November 2014

\section{References}

1. Jumper JM, McDonald R, Johnson RN, Ai E, Fu AD (2006) Serpiginous choroiditis. In: Ryan SJ (ed) Retina, vol 2, 4th edn, chapter 105. Elsevier Mosby, St. Louis, pp 1811-1820

2. Erkkila H, Laatikainen L, Jokinen E (1982) Immunological studies on serpiginous choroiditis. Graefes Arch Clin Exp Ophthalmol 219:131-134

3. Gupta V, Gupta A, Rao NA (2007) Intraocular tuberculosis - an update. Surv Ophthalmol 52:561-587

4. Nazari KH, Rao NA (2013) Serpiginous choroiditis and infectious multifocal serpiginoid choroiditis. Surv Ophthalmol 58:203-232

5. Mohan N, Balne P, Panda KG, Sharma S, Basu S (2014) Polymerase chain reaction evaluation of infectious multifocal serpiginoid choroiditis. Ocular Immunol Inflamm 22(5):384-390

6. Annamalai R, Biswas J, Sudharshan S, Gayathri R, Therese L, Vishwanath S et al (2014) Real time PCR reaction for Mycobacterium tuberculosis in serpiginous choroiditis - a study of 29 cases. Int J Med Res Health Sci 3 (3):530-534

7. Bansal R, Gupta A, Gupta V, Dogra MR, Bambery P, Arora SK (2008) Role of anti-tubercular therapy in uveitis with latent/manifest tuberculosis. Am J Ophthalmol 146:772-779

8. Nandi K, Ranjan P, Therese L, Biswas J (2008) Polymerase chain reaction in intraocular inflammation. Open Ophthalmol J 2:141-145

\section{doi:10.1186/s12348-014-0029-5}

Cite this article as: Shetty et al:: Real-time and nested polymerase chain reaction in the diagnosis of multifocal serpiginoid choroiditis caused by Mycobacterium tuberculosis - a case report. Journal of Ophthalmic Inflammation and Infection 2014 4:29.

\section{Submit your manuscript to a SpringerOpen ${ }^{\circ}$ journal and benefit from:}

- Convenient online submission

Rigorous peer review

- Immediate publication on acceptance

- Open access: articles freely available online

- High visibility within the field

- Retaining the copyright to your article

Submit your next manuscript at springeropen.com 